\title{
Fe Substituted $\mathrm{SrTiO}_{3}$ as Visible Light Active Photosensitive Material for Solar- Hydrogen Generation
}

Radhika T * and Keerthi $\mathrm{K}^{\dagger}$

\begin{abstract}
Perovskite $\mathrm{SrTiO}_{3}$ and $\mathrm{Fe}$ Substituted $\mathrm{SrTiO}_{3}$ were prepared by solid-state reaction route as visible light active photosensitive materials for solar-hydrogen generation applications. Powder X-ray diffraction pattern confirms the formation of crystalline perovskite $\mathrm{SrTiO}_{3}$ phase at sintering temperature of $1273 \mathrm{~K}$. The pattern of Fe substituted $\mathrm{SrTiO}_{3}$ exhibits number of peaks with splits and less crystalline indicating a lower symmetry structure upon substation at $\mathrm{Sr}$ and $\mathrm{Ti}$ sites. Crystallinity and crystallite size also finds decrease with increased $\mathrm{Fe}$ substitution. The band gap of $\mathrm{SrTiO}_{3}$ obtained by DR UVVis absorbance analysis at various sintering temperature approaches the theoretical value $3.06 \mathrm{eV}$. However, on Fe substitution the band gap is reduced to $\sim 2.0-2.5 \mathrm{eV}$ suggesting the materials can extend its absorption to the visible range also. FT-IR spectra confirmed that the Fe substituted $\mathrm{SrTiO}_{3}$ is similar to that of pure phase with bands corresponding to the hydroxyl and carboxyl groups. Since the substituted materials show reduced band gap, these materials can be utilized for photosensitive solar-hydrogen generation.
\end{abstract}

* Scientist B, Centre for Materials for Electronics Technology [C-MET], (Scientific Society under M/o Communications and Information Technology, India) M.G. Kavu P.O., Athani, Thrissur, Kerala, India680581: rads12@gmail.com

† (C-MET); keerthiblkrshn@gmail.com

Received: January 2013; Reviewed: February 2013 
Keywords: Solar-hydrogen, $\mathrm{SrTiO}_{3}, \mathrm{Fe}$ substation, Visible, Photosensitive, Water-splitting

\section{Introduction}

Combustion of fuels in automobiles and power plants generate large number of the health and crop-damaging and global warming air pollutants. There is an urgent need for developing renewable energy resources that can be alternative to fossil fuels (oil, coal etc.) [1]. Solar energy is the only available source of energy capable of continually providing the vast quantities of carbon-free energy that can meet the growing global energy demand. Hydrogen, generated from water using solar energy, solar-hydrogen, is a renewable and environmentally safe energy carrier due to several reasons such as; 1) sunlight and water are renewable 2) materials are inexpensive, 3 ) solar-hydrogen technology is relatively simple and thus the cost of such a fuel is expected to be substantially less than oil, 4) solar energy is the only required energy source for solar-hydrogen generation $[2,3]$. The most critical issue in the development of solarhydrogen is the development of a special class of new photosensitive materials for efficient and clean conversion of solar energy. Sunlight, an unlimited source of clean and renewable energy which can be efficiently utilizes to produce hydrogen, the fuel of the near future by water-splitting. Numerous studies focused on photo electrochemical water-splitting reaction [4]. The enhancement of efficiency of a solar-hydrogen production process is of considerable importance because high efficiency translates into lower costs. It is, therefore, important to search for a stable and low-cost material for efficiently harvesting the solar energy. The high living standard created in the world during the last century is to a large extent due to easy access to cheap fossil fuels. These resources are limited, and the ever increasing energy demands, together with the $\mathrm{CO}_{2}$ related climate problems, make the development of sustainable energy technology one of the most important problems of today. Direct harvesting and conversion of solar light to electrical energy in photovoltaic (PV) cells or to chemical energy by photo electrochemical (PEC) reactions are the most obvious technologies to address this problem [5]. Hydrogen is currently produced from fossil fuels on an industrial scale. 
However, much attention has been focused on the direct splitting of water for $\mathrm{H}_{2}$ generation [6]. Photosensitive overall splitting of water using solar energy has been extensively investigated to solve the energy and environmental issues at a global level. Conventionally, both technologies rely on light collection in semiconductor materials with appropriate band gaps that match the solar spectrum in order to obtain high energy conversion efficiency.

To use semiconductors as possible photosensitive material, their viability depends on their ability to absorb enough sunlight as well as their stability against photo corrosion [7]. The electronic structure of a semiconductor plays a key role in its photo activity. Unlike a conductor, a semiconductor consists of a valence band (VB) and the conduction band CB). Energy difference between these two levels is said to be the band gap (Eg). For efficient $\mathrm{H}_{2}$ production using a visible-light-driven semiconductor (Figure 1), the band gap should be less than $3.0 \mathrm{eV}$, but larger than $1.23 \mathrm{eV}$ [8].

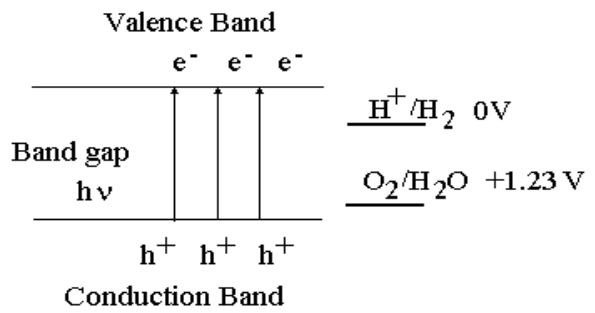

Figure 1: Band gap structure of a semiconductor

Moreover, the conduction band (CB) and valence band (VB) levels should satisfy the energy requirements set by the reduction and oxidation potentials for $\mathrm{H}_{2} \mathrm{O}$ respectively. For $\mathrm{H}_{2}$ production, the $\mathrm{CB}$ level should be more negative than $\mathrm{H}_{2}$ production level $\mathrm{E}_{\mathrm{H} 2 \mathrm{O} / \mathrm{H} 2}$ while the VB should be more positive than water oxidation level $\mathrm{E}_{\mathrm{H} 2 \mathrm{O} / \mathrm{O} 2}$ for efficient oxygen production from water by photosensitive reaction.

The photosensitive material must be stable in aqueous solutions under photo irradiation. Oxide semiconductors are generally highly stable against photo corrosion and have thus been extensively used as heterogeneous photosensitive materials. However, Scaife noted in 1980 that it is intrinsically difficult to 
develop an oxide semiconductor photosensitive material that has both a sufficiently negative conduction band for $\mathrm{H}_{2}$ production and a sufficiently narrow band gap (i.e., $<3.0 \mathrm{eV}$ ) for visible light absorption because of the highly positive valence band (at ca. +3.0 $\mathrm{V}$ vs. NHE) formed by the $\mathrm{O} 2 \mathrm{p}$ orbital. Indeed, most visible-lightresponsive oxide photosensitive material, such as tungsten oxide $\left(\mathrm{WO}_{3}\right)$ or bismuth vanadate $\left(\mathrm{BiVO}_{4}\right)$, cannot produce $\mathrm{H}_{2}$ from water due to their conduction bands being too low for water reduction [9]. Although some non-oxide semiconductors, such as sulfides and nitrides, posses appropriate band levels for water-splitting under visible light these are generally unstable and readily become deactivated through photo corrosion or self-oxidation, rather than evolving $\mathrm{O}_{2}$. For example, cadmium sulfide (CdS) has appropriate band levels for water reduction and oxidation as well as a narrow band gap that permits visible light absorption [10].

Ever since Fujishima and Honda reported photo electrochemical water-splitting using a $\mathrm{TiO}_{2}$ electrode in 1972 [11], numerous researchers have intensively studied water-splitting using semiconductor photo electrodes or photosensitive materials. In such systems, light energy is converted into chemical energy and the Gibbs free energy increases greatly. Since photosensitive or photoelectrochemical water-splitting resembles photosynthesis in green plants it is regarded as being a form of artificial photosynthesis [12]. Heterogeneous photosensitive systems that use semiconductor powders have several advantages over photoelectrochemical systems, including greater simplicity and lower cost. Consequently, extensive efforts have been made to develop efficient heterogeneous photosensitive materials by investigating new semiconductor materials. Although more than 100 photosensitive systems based on metal oxides have been reported to be active for "overall" water splitting (i.e., simultaneous generation of both $\mathrm{H}_{2}$ and $\mathrm{O}_{2}$ ), most of these materials active only under ultraviolet (UV) light $(\lambda<400 \mathrm{~nm})$ because of the large bandgap energy of semiconductor materials. Since nearly half of the solar energy incident on the Earth's surface lies in the visible region $(400<\lambda<800 \mathrm{~nm})$ it is essential to use visible light efficiently to realize practical $\mathrm{H}_{2}$ production on a huge scale by photosensitive water-splitting. The maximum solar conversion efficiency for 
photosensitive water-splitting with a quantum efficiency of $100 \%$ can be calculated using the standard solar spectrum. Even if all UV light up to $400 \mathrm{~nm}$ were utilized, the solar conversion efficiency would be only $4 \%$, which is similar to the maximum conversion efficiencies of photosynthesis in green plants under normal environmental conditions (1-2\%). However, the utilization of visible light up to $600 \mathrm{~nm}$ can drastically improve the efficiency to $16 \%$; a further extension up to $800 \mathrm{~nm}$ would give a conversion efficiency of $32 \%$ [13].

Over the past several decades many photosensitive materials reported to exhibit high photosensitive activities for splitting water into a stoichiometric mixture of $\mathrm{H}_{2}$ and $\mathrm{O}_{2}$ [14]. Among the vast majority of active photosensitive materials perovskite type compounds such as $\mathrm{SrTiO}_{3}$ [15], $\mathrm{K}_{2} \mathrm{La}_{2} \mathrm{Ti}_{3} \mathrm{O}_{10}$ [16], $\mathrm{NaTaO}_{3}$ [17], and $\mathrm{RbNdTa}_{2} \mathrm{O}_{7}$ [18] have been proven to be active for water-splitting. Unfortunately, their practical applications have been restricted to the ultraviolet region due to their large band gap $(>3.0 \mathrm{eV})$, which occupies only about $4 \%$ of the solar spectrum. In recent years substituting foreign elements into a semiconductor with a wide band gap to extend to the optical absorption edge has been known to be one of the effective strategies for developing photosensitive materials available for visible light-driven water-splitting [19]. Recently various cation or anion doped perovskite type compounds have been synthesized and activities under visible light have been investigated experimentally [20].

Generally photosensitive materials require high surface area, high optical absorption capability and chemical stability in addition to being non-toxic. Another important thermodynamic factor for water-splitting is that the photosensitive materials have higher reduction and oxidation potentials of its valance and conduction band edges compared to those of pure water $\left[\mathrm{E}_{\left(\mathrm{O}_{2} / \mathrm{H}_{2} \mathrm{O}\right)}=+1.23 \mathrm{eV}\right.$, $\mathrm{E}_{\left(\mathrm{H}_{2} \mathrm{O} / \mathrm{H}_{2}\right)}=0 \mathrm{eV}$ ]. Among these properties, the optical absorption properties and band positions are the most important factors for the photosensitivity and are strongly related to the crystal structure [21].

It has been reported that some metal oxides show reasonable activities for water-splitting into $\mathrm{H}_{2}$ and $\mathrm{O}_{2}$ in a stoichiometric ratio under UV light irradiation [22]. However the number of 
photosensitive material is still limited and active materials being employed are mainly titanates [23]. Therefore further investigation of photosensitive material for water-splitting is indispensable for revealing essential factors of active photosensitive materials and getting a guiding principle of development of new photosensitive materials. In particular, photosensitive water-splitting has attracted much interest as a method of producing hydrogen $\left(\mathrm{H}_{2}\right)$ under light illumination and has been studied extensively [24].

Among the vast majority of metal oxide photosensitive materials, perovskite oxides are prominent for their diversity of properties [25]. $\mathrm{SrTiO}_{3}(\mathrm{STO})$ is a promising perovskite type photosensitive material for water decomposition under sunlight, because of its optical and electrical properties, chemical stability and non-toxicity. At room temperature it exists in the cubic form, but transforms into the tetragonal structure at temperatures less than $105 \mathrm{~K}$. STO is a dielectric material, and is used as a photosensitive material to degrade organic pollutants or split water to produce $\mathrm{H}_{2}$ and $\mathrm{O}_{2}$ [26]. Perovskite type STO provides a higher potential and facilitates the formation of $\mathrm{H}_{2}$ and $\mathrm{O}_{2}$ [27]. STO as a photosensitive material could be used to produce hydrogen under UV light. Pure STO without an additive shows a very low photosensitive activity. It has been active only under UV light irradiation owing to its wide band gap (389 $\mathrm{nm}$ ). This limitation can be overcome by substituting other elements. Transition metals such as $\mathrm{Fe}, \mathrm{Co}, \mathrm{Mn}, \mathrm{Pt}, \mathrm{Ru}$ have been substituted into STO to allow visible light absorption [28], which effects the lattice structure, electronic configuration, surface morphology and surface area of photosensitive material etc. It is reported that STO co-doped with $\mathrm{N}_{2}$ and La exhibit high photosensitivity due to the decrease of the oxygen vacancies, which may act as electron-hole pair recombination centers, because codoping with $\mathrm{La}^{3+}$ and $\mathrm{N}^{3-}$ ions maintained the charge balance [29]. Another report suggests that $\mathrm{Cr}$ substitution in STO introduces $\mathrm{d}$ state within the band gap [30] and investigates the synergistic effect of some non-metal and metal on N-substituted STO [31]. It is also reported that transition metals [Mn, Fe and $\mathrm{Co}$ ] substitution in STO introduce d states within the band gap [32]. According to a study, the transition metals such as Fe/Co substitution in STO introduce d states within the band gap [33]. Some 3d states of Co appear below 
the bottom of the conduction band, and some $3 \mathrm{~d}$ states of Fe are located above the top of the valance band, which results in the decreased band gap with respect to the perfect STO and thus the visible light absorption is observed [34].

For most of the photosensitive materials, it is necessary to load transition metal co-catalysts for overall water-splitting. The yield of $\mathrm{H}_{2}$ gas by these catalysts still settles in magnitude of micromole $\mathrm{h}^{-1} \mathrm{~g}^{-1}$, which renders the overall process impractical [35]. Therefore it is still very important to find new photosensitive materials with high photo activity inorder to make the water-splitting a viable method to provide clean and renewable source for $\mathrm{H}_{2}$, fuel in the future.

The present work deals with an initial stage of visible light active perovskite materials preparation for solar-hydrogen generation applications. STO and Fe substituted STO were prepared via solidstate reaction method. The materials were characterized using various physico-chemical techniques such as X-ray Diffraction, DR UV-Visible spectroscopy and FT-IR spectroscopy etc inorder to apply as photosensitive materials for solar-hydrogen generation.

\section{Experimental}

All the chemicals used in this study were analytical grade and used as received. The materials used for the preparation of the photosensitive materials are; $\mathrm{SrCO}_{3}$ (99.9\%; Merck Ltd., Mumbai), $\mathrm{TiO}_{2}$ (Sigma Aldrich, Anatase, Merck Ltd., Mumbai), and $\mathrm{Fe}\left(\mathrm{NO}_{3}\right)_{3} .9 \mathrm{H}_{2} \mathrm{O}$ - (98\%, Merck Ltd., Mumbai). Distilled water was used as the solvent in all the preparations.

The materials were prepared by employing solid-state reaction method. In this method, the required amount of $\mathrm{SrCO}_{3}$ and $\mathrm{TiO}_{2}$ were mixed through an agate mortar with the addition of suitable amount of distilled water as solvent. The resulted white color slurry was dried under an infra-red lamp. The dried solid material was sintered at the required temperature in a programmed muffle furnace.

The same procedure was followed for the preparation of $\mathrm{Sr}_{(1-\mathrm{x})} \mathrm{M}_{(\mathrm{x})} \mathrm{TiO}_{2}$ and $\operatorname{SrM}_{(\mathrm{x})} \mathrm{Ti}_{(1-\mathrm{x})} \mathrm{O}_{2} \quad(\mathrm{M}=\mathrm{Fe})$ where the solid-state 
mixing was carried out using various concentrations $(x=0.2,0.4$, $0.6,0.8,0.5,1.0)$ of the substituent. The solid mass obtained after drying under infra-red lamp was subjected for sintering at required temperature. After sintering the powder obtained was grounded and used for further studies. The materials prepared with notations are presented in Table 1.

\begin{tabular}{|c|c|c|}
\hline Sl. No. & Materials & Notations \\
\hline 1. & $\begin{array}{l}\mathrm{SrTiO}_{3}(\text { Calc. at } 1173, \\
1273,1373 \text { and } 1473 \mathrm{~K})\end{array}$ & $\mathrm{SrTiO}_{3}(1173 \mathrm{~K})$ \\
\hline 2. & \multirow{3}{*}{ Sr substituted with Fe } & $\mathrm{Sr}_{0.2} \mathrm{Fe}_{0.8} \mathrm{TiO}_{3}$ \\
\hline 3. & & $\mathrm{Sr}_{0.4} \mathrm{Fe}_{0.6} \mathrm{TiO}_{3}$ \\
\hline 4. & & $\mathrm{Sr}_{0.5} \mathrm{Fe}_{0.5} \mathrm{TiO}_{3}$ \\
\hline 5. & \multirow{3}{*}{ Ti substituted with Fe } & $\mathrm{SrFe}_{0.2} \mathrm{Ti}_{0.8} \mathrm{O}_{3}$ \\
\hline 6. & & $\mathrm{SrFe}_{0.4} \mathrm{Ti}_{0.6} \mathrm{O}_{3}$ \\
\hline 7. & & $\mathrm{SrFe}_{0.5} \mathrm{Ti}_{0.5} \mathrm{O}_{3}$ \\
\hline 8. & & $\mathrm{SrFeO}_{3}$ \\
\hline
\end{tabular}

Table 1: Materials prepared with notations

\subsection{Characterization}

All the materials were characterized by various techniques. The Powder X-ray diffraction pattern of the materials were obtained on an AXS Bruker D5005 X-ray diffractometer (Germany) with a vertical goniometer- ray generator operated at $40 \mathrm{kV}$ and $30 \mathrm{~mA}$, $\mathrm{CuKa}\left(\lambda=1.5418 \mathrm{~A}^{\circ}\right)$ radiation with $\mathrm{Ni}$ filter. The absorbance and reflectance spectra were recorded on DR UV-Visible-NIR spectrometer (Varian\ cary 5000). The FT-IR spectra were recorded on Perkin Elmer over the range $400-4000 \mathrm{~cm}^{-1}$.

\section{Results and Discussion}

The Figure 2 shows the diffraction pattern of STO calcined at different temperatures. In solid-state method, most heating energy was consumed for transportation and rearrangement of $\mathrm{Ti}, \mathrm{O}$ and $\mathrm{Sr}$ atoms until cubic STO nuclei form. The pattern of STO calcined at high temperatures is confirmed with that of STO JCPDS (JCPDS No:35-0734). The temperature of $1273 \mathrm{~K}$ is required to form the perovskite structure when the oxide is prepared by solid-state method. The STO calcined at temperatures of $1273 \mathrm{~K}$ and $1373 \mathrm{~K}$ is 
identical. No other impurity phases were observed. The pattern of STO (1273K) was indexed on an orthorhombic cell with pm3m space group. The strongest diffraction peak located at $32.40^{\circ}$ belongs to (110) plane. All the pattern were compared with JCPDS of STO (No:35-0734). Following the observations, $1273 \mathrm{~K}$ was selected as the sintering temperature for further treatment of the substituted materials.

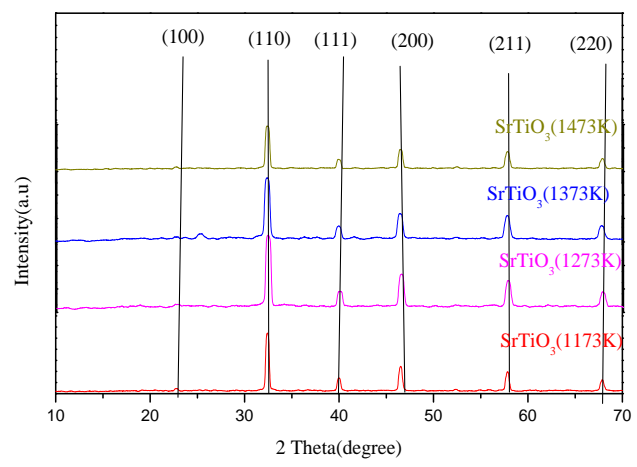

Figure 2 : Powder X-ray diffraction pattern of STO calcined at different temperatures.

The powder diffraction patterns of the Fe substituted STO are presented in Figure 3. As shown in the pattern, the main peaks of STO remain the same with Fe substitution for both $\mathrm{Sr}$ and Ti sites in the host lattice. The perovskite nature of the materials is retained even after substitution but there are some changes in the degree of crystallinity depending on the metal and site of substitution. The ionic radius of $\mathrm{Ti}^{4+}$ is $0.060 \mathrm{~nm}$ and that of $\mathrm{Fe}^{3+}$ is $0.061 \mathrm{~nm}$, which indicates that $\mathrm{Fe}^{3+}$ ion can be easily substituted into the lattice. As the amount of $\mathrm{Fe}$ substitution increased, pattern becomes less crystalline in nature. 


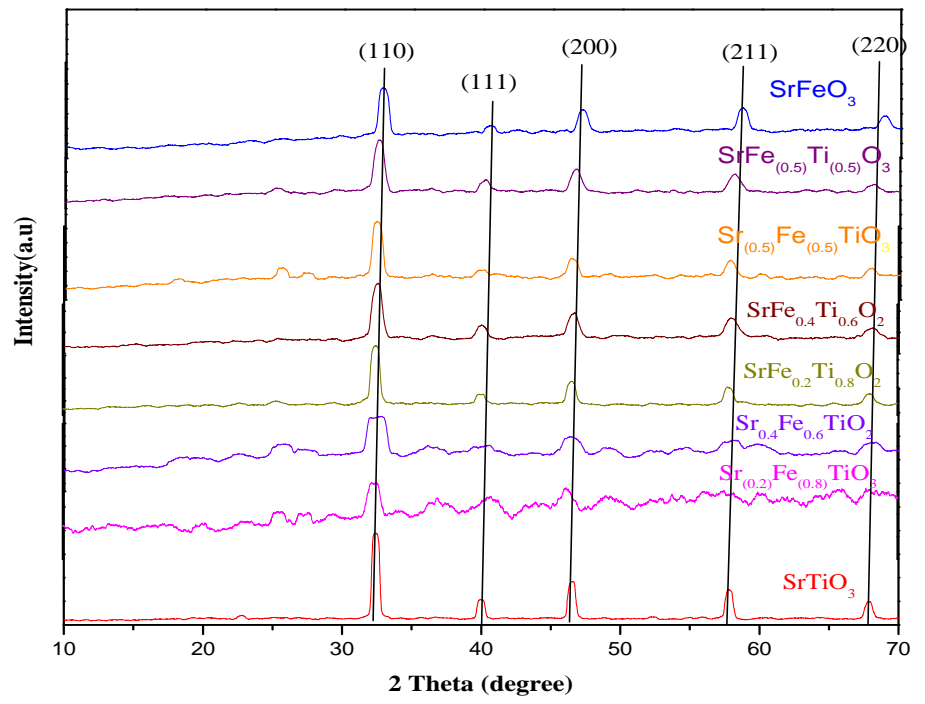

Figure 3: Powder X-ray diffraction patterns of Fe substituted STO.

The pattern of Fe substituted in the $\mathrm{Sr}$ site shows almost all perovskite peaks. A reduction in the crystallinity may arise due to the difference in ionic radius of $\mathrm{Fe}^{3+}$ and $\mathrm{Sr}^{2+}$. The ionic radius of $\mathrm{Sr}^{2+}(0.118 \mathrm{~nm})$ is greater than that of $\mathrm{Fe}^{3+}(0.064 \mathrm{~nm})$. The $(110)$ plane indicates that the existence of perovskite structure. Low intense peak were disappeared due to high substitution on $\mathrm{Sr}^{2+}$ and also the ionic radius was different. The pattern of $\mathrm{SrFeO}_{3}$ reveals its perovskite structure.

The XRD pattern consists of several low intensity peaks corresponding to pure phase. The observed peaks were correlated to JCPDS file. The higher intensity of (100) plane can be attributed to a sintering effect that boosts the crystallinity and specific orientation of crystallites. Significantly there are a number of peaks with clear splits, indicating the transformation of the cubic perovskite structure of STO into a low symmetry. This lowered symmetry, due to the addition of Fe at $\mathrm{Ti}$ site could induce nocentrosymmetry. The addition of Fe can induce strains in the lattice due to the slight mismatch in the ionic radius [36]. The lattice defect depends on $\mathrm{Sr} / \mathrm{Ti}$ atomic ratio. When $\mathrm{Sr} / \mathrm{Ti}$ atomic ratio is smaller than 1, Sr deficient STO might be formed, whereas when $\mathrm{Sr} / \mathrm{Ti}$ atomic ratio was greater than 1 , Ti deficient STO might be formed [37]. The XRD patterns (figures 3 ) confirm that the Fe substitution 
in the STO crystal lattice does not change the basic perovskite structure (position, intensity), although some change is observed in the crystallinity.

Crystallite size of the prepared materials was calculated using Scherrer equation. The obtained crystallite sizes are presented in Table 2 . The crystallite size of STO $(\sim 47 \mathrm{~nm})$ did not change much with various sintering temperatures (1173-1473 K).

The substitution of $\mathrm{Fe}$ both in the $\mathrm{Sr}$ and $\mathrm{Ti}$ sites reduced the crystallite size. As the amount of Fe substitution increases, the crystallite size found to be decrease considerably. This may arise due to the difference in ionic radius of the substituted Fe.

\begin{tabular}{|c|l|c|}
\hline Sl. No. & \multicolumn{1}{|c|}{ Materials } & Crystallite size (nm) \\
\hline 1. & $\mathrm{SrTiO}_{3}(1173 \mathrm{~K})$ & 44.8 \\
\hline 2. & $\mathrm{SrTiO}_{3}(1273 \mathrm{~K})$ & 47.4 \\
\hline 3. & $\mathrm{SrTiO}_{3}(1373 \mathrm{~K})$ & 47.4 \\
\hline 4. & $\mathrm{SrTiO}_{3}(1473 \mathrm{~K})$ & 49.4 \\
\hline 5. & $\mathrm{Sr}_{0.2} \mathrm{Fe}_{0.8} \mathrm{TiO}_{3}$ & 19.7 \\
\hline 6. & $\mathrm{Sr}_{0.4} \mathrm{Fe}_{0.6} \mathrm{TiO}_{3}$ & 29.1 \\
\hline 7. & $\mathrm{Sr}_{0.5} \mathrm{Fe}_{0.5} \mathrm{TiO}_{3}$ & 34.4 \\
\hline 8. & $\mathrm{SrFe}_{0.2} \mathrm{Ti}_{0.8} \mathrm{O}_{3}$ & 40.9 \\
\hline 9. & $\mathrm{SrFe}_{0.4} \mathrm{Ti}_{0.6} \mathrm{O}_{3}$ & 28.4 \\
\hline 10. & $\mathrm{SrFe}_{0.5} \mathrm{Ti}_{0.5} \mathrm{O}_{3}$ & 27.4 \\
\hline 11. & $\mathrm{SrFeO}_{3}$ & 37.3 \\
\hline
\end{tabular}

Table 2: Crystallite size of prepared materials

The DR UV-Visible spectra of synthesized STO through solid state reaction method are shown in figure 4. According to the plot of wavelength $(\mathrm{nm})$ versus absorbance, the band gap of STO obtained. According to the theoretical approach, the energy band of the STO materials is estimated to about $3.2 \mathrm{eV}$ [38].

The band gap of the materials was calculated using the formula and are presented in Table 3.

$$
\text { Band gap }=\mathrm{hc} / \lambda
$$

The band gap energies of the as prepared STO materials can be obtained from the wavelength values corresponding to the intersection point of the vertical and horizontal parts of DR UV-VIS spectra using the equation. 


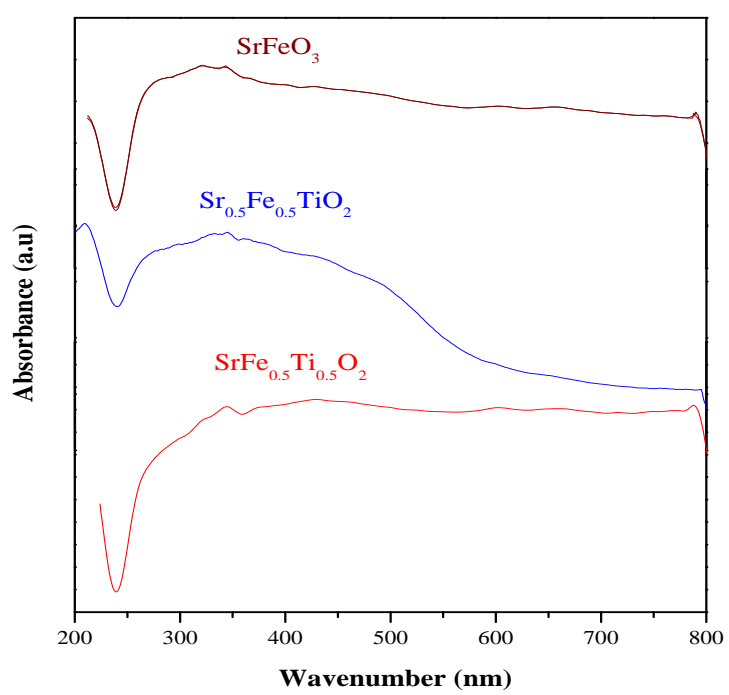

Figure 4: DR-UV-Visible spectra of Fe substituted STO

\begin{tabular}{|c|l|c|}
\hline Sl.No. & \multicolumn{1}{|c|}{ Materials } & Band Gap (eV) \\
\hline 1. & $\mathrm{SrTiO}_{3}(1173 \mathrm{~K})$ & 3.06 \\
\hline 2. & $\mathrm{SrTiO}_{3}(1273 \mathrm{~K})$ & 3.00 \\
\hline 3. & $\mathrm{SrTiO}_{3}(1373 \mathrm{~K})$ & 3.06 \\
\hline 4. & $\mathrm{SrTiO}_{3}(1473 \mathrm{~K})$ & 3.09 \\
\hline 5. & $\mathrm{Sr}_{0.5} \mathrm{Fe}_{0.5} \mathrm{TiO}_{3}$ & 2.65 \\
\hline 6. & $\mathrm{SrFe}_{0.5} \mathrm{Ti}_{0.5} \mathrm{O}_{3}$ & 2.48 \\
\hline 7. & $\mathrm{SrFeO}_{3}$ & 2.29 \\
\hline
\end{tabular}

Table 3: Band gap of the materials

The pure STO prepared shows an absorbance at $405 \mathrm{~nm}$ indicating that the band gap is $3.06 \mathrm{eV}$. There is not much changes observed in the band gap with various sintering temperature (figure not shown). The Fe substituted STO shows bathochromic shift in absorption. Band gap energies of the prepared materials are summarized in Table 3. As noted in the table, the pure material shows a band gap value of $3.06 \mathrm{eV}$. The band gap energy of Fe substituted STO materials shows a decrease. Upon Fe substitution, 
the band gap energy is decreased to 2.65, 2.48 and $2.29(\mathrm{eV})$ for $\mathrm{Sr}_{0.5} \mathrm{Fe}_{0.5} \mathrm{TiO}_{3}, \mathrm{SrFe}_{0.5} \mathrm{Ti}_{0.5} \mathrm{O}_{3}, \mathrm{SrFeO}_{3}$ respectively. This suggests the effect of element substitution in altering the band gap energy of the semiconductor STO.

It can be seen that the band gap of STO at different sintering temperatures are nearly at the theoretical value. On Fe substitution the band gap is reduced so that the materials become visible light active, the efficiency of the photosensitive material become increased. This extended absorbance of Fe substituted STO materials into the visible region $(2.0-2.5 \mathrm{eV})$ provides a possibility of enhancing the photosensitive behavior of STO for water-splitting to produce solar hydrogen applications as well.

The FT-IR spectra recorded for STO and Fe substituted STO are shown in figure 5 .

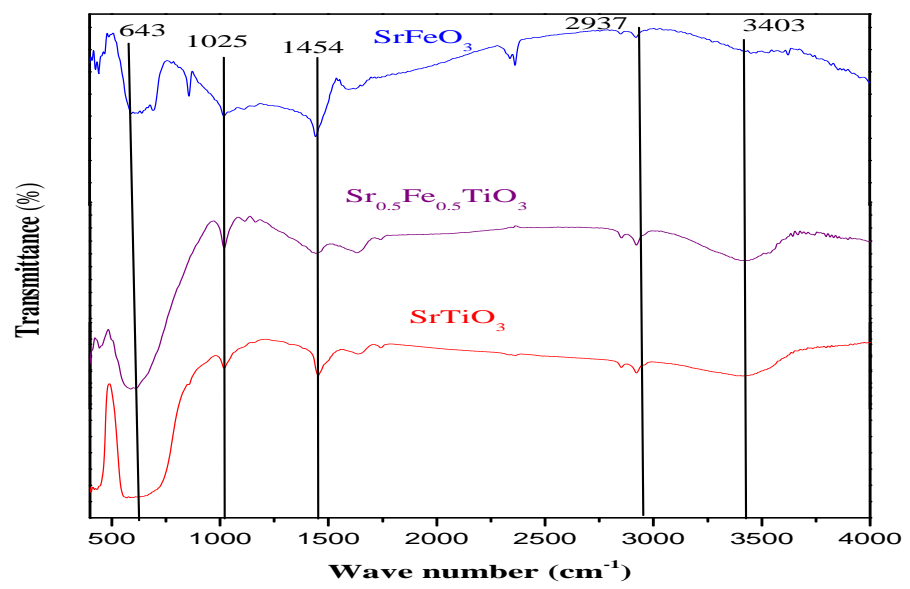

Figure 5: FT-IR spectra of the prepared materials

The FT-IR spectra of pure STO prepared by the solid state reaction method shows an intense peak at $643 \mathrm{~cm}^{-1}$, which is attributed to the vibration of the Ti-O units in anatase phase [39]. The peak at $1454 \mathrm{~cm}^{-1}$ indicates the bending mode of $\mathrm{OH}$ or the adsorbed water on the STO surface [40]. 
On Fe substitution, corresponding peak at $643 \mathrm{~cm}^{-1}$ observed in less intense and as very broad in $\mathrm{SrFeO}_{3}$. However, the peak at $1454 \mathrm{~cm}^{-1}$ is less intense in Fe substituted STO while appears more intense in $\mathrm{SrFeO}_{3}$. This result indicates that on substitution crystallinity has changed but the crystal structure is almost identical. The band in the region 1600 to $3000 \mathrm{~cm}^{-1}$, is almost flat in STO and also in Fe substituted phase, but in $\mathrm{SrFeO}_{3}$ it is not. The characteristic change may observe due to the $\mathrm{CO}_{2}$ evolution and $\mathrm{OH}$ action in $\mathrm{SrFeO}_{3}$. This red-shift may be due to electron donating effect of the alkaline earth metal ion, $\mathrm{Sr}^{2+}$. The low frequency band at $3403 \mathrm{~cm}^{-1}$ can be assigned to either Ti-OH perturbed at nearby $\mathrm{Sr}$ atom or to $\mathrm{Sr}-\mathrm{OH}$ groups [41]. The extra peak in $\mathrm{SrFeO}_{3}$ at $2366 \mathrm{~cm}^{-1}$, may due to the $\mathrm{CO}_{2}$ comes from the environment. In short it can be observed from FT-IR spectra that crystallinity changes with substitution and $\mathrm{Ti}$ backbone plays a significant role in the material structure.

The further study will be conducted for hydrogen generation by water-splitting under a source of visible light. Later the same materials will be used for hydrogen generation under solar light to produce solar-hydrogen, the fuel of the near future.

\section{Conclusion}

The powder X-ray diffraction evidenced the formation of highly crystalline perovskite STO phase at sintering temperature of 1273 K. The pattern of Fe substituted STO exhibits a number of peaks with splits, indicating the transformation of the cubic perovskite structure of STO into a lower symmetry. Crystallinity was decreased with increased $\mathrm{Fe}$ substitution. Crystallite size calculation suggests that as the substitution increases, the crystal size decreases. The band gap by DR UV-Vis absorbance analysis for STO at various sintering temperature approaches the theoretical value $3.06 \mathrm{eV}$. However, a reduction in band gap was observed upon Fe substitution to $\sim 2.0-2.5 \mathrm{eV}$ suggesting that the materials can absorb in the visible range also. The absorbance spectra analysis of the Fe substituted STO is promising towards visible light active photosensitive applications especially for solarhydrogen generation. FT-IR spectra confirmed that the substituted 
STO is similar to that of pure phase with bands corresponding to the hydroxyl and carboxyl groups. The materials prepared using this simple solid-state method is found to be highly crystalline. Further studies of these materials for solar-hydrogen generation in a photoreactor set up is under progress.

\section{Acknowledgement}

The authors gratefully acknowledge the facilities provided by C-MET, Thrissur, Kerala during this work.

\section{References}

[1] J. Nowotny and L. R. Sheppard,"Solar-hydrogen," Int. J. Hydrogen Energy. vol. 32, pp. 2607-2608, Sept. 2007. doi:10.1016/ j.ijhydene.2006.09.003

[2] J. Nowotny, C. C. Soreell, L. R. Sheppard and T. Bak, "Solar-hydrogen: Environmentally safe fuel for the future," Int. J. Hydrogen Energy. vol. 30, pp. 521-544, Apr. 2005. doi:10.1016/j.ijhydene.2004.06.012

[3] H. I. Karunadasa, C. J. Chang and J.R. Long, "A molecular molybdenum-oxo catalyst for generating hydrogen from water," Nature, vol. 464, pp.1329-1333, Apr. 2010. doi: 10.1038/nature08969.

[4] M. A. Pena and J. L. G. Fierro, Chemical Structures and Performance of Perovskite Oxides Chem. Rev., vol. 101 (7), pp. 1981-2018, May 2001. doi:10.1021/cr980129f

[5] I. B. Bersuker, The Jahn-Teller Effect, Cambridge Univ Pr, 2006.

[6] M. S. Wrighton, A. B. Ellis, P. T. Wolczanski, D. L. Morse, H. B Abrahamson and D. S. Ginley, "Strontium titanate photoelectrodes. Efficient photoassisted electrolysis of water at zero applied potential," J. Am. Chem. Soc., vol. 98, pp. 2774-2779, May 1976. doi:10.1021/ja00426a017

[7] J. D. G Fernandes, D. M. A Melo, L. B Zinner, C. M Salustiano, Z. R Silva, A. E Martinelli, M Cerqueira, C Alves Júnior, E Longo, and M. I. B Bernardi, "Low-temperature synthesis of single-phase crystalline $\mathrm{LaNiO}_{3}$ perovskite via Pechini method," Materials Letters, vol. 53, pp. 122-125, March 2002. doi:10.1016/S0167-577X(01)00528-6

[8] X. Niu, H. Li, and G. Liu, "Preparation, characterization and photocatalytic properties of $\mathrm{REFeO}_{3}(\mathrm{RE}=\mathrm{Sm}, \mathrm{Eu}, \mathrm{Gd})$," Journal of 
Molecular Catalysis A: Chemical, vol. 232, pp. 89-93, May 2005. doi:10.1016/j.molcata.2005.01.022

[9] N. Minh "Solid oxide fuel cell technology-features and applications: Review Article," Solid State Ionics, vol. 174, pp. 271-277, Oct. 2004. doi:10.1016/j.ssi.2004.07.042

[10]N. Keller, J. Mistrík, S. Visnovský, D. S. Schmool, Y. Dumont, P. Renaudin, M. Guyot and R. Krishnan, "Magneto-optical Faraday and Kerr effect of orthoferrite thin films at high temperatures," Eur. Phys. J. B., vol. 21, pp. 67-73, May (2001). doi:10.1007/s100510170214

[11]N. Kojima and K. Tsushima, "Recent progress in magneto-optics and research on its applications" Low Temp. Phys., (Review) vol.28, pp. 480, 2002. doi:10.1063/1.1496656

[12]H. Sakakima, M. Satomi, E. Hirota, and H. Adachi, "Spin-valves using perovskite antiferromagnets as the pinning layers ", IEEE Trans. Magn. Vol. 35, pp. 2958-2960, 2002. doi:10.1109/20.801046

[13] C. Alcock, R. Doshi and Y. Shen, " Perovskite electrodes for sensors", Solid State Ionics vol. 51, pp. 281, 1992. doi:10.1016/01672738(92)90210-G,

[14]L. H. Brixner, "Preparation and properties of the SrTi1 _ Fe OO3 _ /24x/2 system", Mater. Res. Bull. Vol. 3, pp. 299, 1968.

[15] K. Sahner, D. Schonauer, R. Moos, M. Matam and M. L. Post, “Effect of Electrodes and Zeolite Cover Layer on Hydrocarbon Sensing with p-Type Perovskite $\mathrm{SrTi}_{0.8}-\mathrm{Fe}_{0.2} \mathrm{O}_{3-\delta}$ Thick and Thin Films," Journal of Materials Science, Vol. 41, No. 18, pp. 5828-583, 2006. doi:10.1007/s10853-006-0299-x

[16]W. Menesklou, H. J. Schreiner, K. H. Härdtl and E. Ivers-Tiffée, “High temperature oxygen sensors based on doped $\mathrm{SrTiO}_{3}$ ", Sens. Actuators, $B$ Vol. 59, No. 2, pp. 184-189(6), October 1999. doi:10.1016/S09254005(99)00218-X

[17]S. Steinsvik, R. Bugge, J. Gjonnes, J. Tafto and T. Norby, “The defect structure of SrTi1-xFexO3-y $(x=0.0 .8)$ investigated by electrical conductivity measurements and electron energy loss spectroscopy (EELS)", J. Phys. Chem. Solids Vol. 58, No. 6, pp. 969.

[18]K. Sahner, R. Moos, M. Matam, J. J. Tunney and M. Post, "Hydrocarbon sensing with thick and thin film p-type conducting perovskite materials", Sens. Actuators, B, Vol. 108, pp. 102 -112, 2005. doi:10.1016/j.snb.2004.12.104 
[19] S. J. Skinner and J. A. Kilner, "Oxygen ion conductors", Mater. Today Vol. 6, No. 6, pp. 30-37, 2003. doi:10.1016/S1369-7021(03)00332-8

[20] J. R. Jurado, F. M. Figueiredo, B. Gharbage and J. R. Frade, "Electrochemical permeability of $\mathrm{Sr}_{0.7}(\mathrm{Ti}, \mathrm{Fe}) \mathrm{O}_{3-\delta}$ materials", Solid State Ionics, Vol. 118, pp. 89, 1999. doi:10.1016/S0167-2738(98)00471-8

[21] V. Varadan, D. Ghodgaonkar, V. Varadan, J. Kelly and P. Glikerdas, "Ceramic phase shifters for electronically steerable antenna systems," Microw. J. vol. 35, pp. 116-127, 1992.

[22] A. Verma, A. Kumar and S. Bhardwaj, "Correlation between ionic charge and the lattice constant of cubic perovskite solids," Phys.Status Solidi B, vol. 245 pp. 1520-1526, 2008. doi:10.1002/pssb.200844072

[23] L. B. McCusker, R. B. Von Dreele, D. E. Cox, D. Louer and P. Scardi, "Rietveld refinement guidelines," J. Appl. Crystallogr., Vol. 32, pp. 3650, 1999. doi:10.1107/S0021889898009856

[24] K. Honda and A. Fujishima ,"Electrochemical Photolysis of Water at a Semiconductor Electrode," Nature, vol. 238, pp. 37-38, 1972. doi:10.1038/238037a0

[25] A. Millis, B. I. Shraiman and R. Mueller, "Dynamic Jahn-Teller Effect and Colossal Magnetoresistance in $\mathrm{La}_{1-x} \mathrm{Sr}_{\mathrm{x}} \mathrm{MnO}_{3}$,"Phys. Rev. Lett, vol. 77, pp. 175-178, 1996. doi:10.1103/PhysRevLett.77.175

[26]O. Haas, F. Holzer, S. Müller, J. McBreen, X. Yang, X. Sun and M. Balasubramanian, "X-ray absorption and diffraction studies of $\mathrm{La}_{0.6} \mathrm{Ca}_{0.4} \mathrm{CoO}_{3}$ perovskite, a catalyst for bifunctional oxygen electrodes," Electrochim. Acta, vol. 47, pp. 3211-3217, 2002. doi:10.1016/S0013-4686(02)00241-4,

[27]I. R. Shein, V. L. Kozhevnikov and A. L. Ivanovskii, "The influence of oxygen vacancies on the electronic and magnetic properties of perovskite-like SrFeO3-X,"J. Phys. Chem. Solids, vol. 67, pp. 14361439, 2006. doi:10.1016/j.jpcs.2006.01.108

[28] Y. Joly, D. Cabaret, H. Renevier and C. Natoli, "Electron Population Analysis by Full Potential X-ray Absorption Simulation," Phys. Rev. Lett, vol. 82, pp. 2398-2401, 1999. doi:10.1103/PhysRevLett.82.2398

[29] R. Vedrinskii, V. Kraizman, A. Novakovich, P. Demekhin and S. Urazhdin, "Pre-edge fine structure of the $3 \mathrm{~d}$ atom $\mathrm{K}$ x-ray absorption spectra and quantitative atomic structure determinations for ferroelectric perovskite structure crystals," J. Phys. Condens, Matter 10, pp. 9561-9580, 1998. doi:10.1088/0953-8984/10/42/021 
[30]T. Yamamoto, T. Mizoguchi and I. Tanaka, "Core-hole effect on dipolar and quadrupolar transitions of $\mathrm{SrTiO}_{3}$ and $\mathrm{BaTiO}_{3}$ at Ti Kedge,"Phys. Rev. B, vol. 71, pp. 245113, 2005. doi: 10.1103/PhysRevB.71.245113

[31] D. Cabaret, B. Couzinet, A. Flank, J. Itie, P. Lagarde and A. Polian, “Ti K Pre-Edge in SrTiO3 under Pressure: Experiments and Full-Potential First-Principles Calculations," XAFS 13 (882), pp. 120-122, 2007. doi: $10.1063 / 1.2644447$

[32] M. Vracar, A. Kuzmin, R. Merkle, J. Purans, E. Kotomin, J. Maier and O. Mathon, "Jahn-Teller distortion around $\mathrm{Fe}^{4+}$ in $\mathrm{Sr}\left(\mathrm{Fe}_{\mathrm{x}} \mathrm{Ti}_{1-\mathrm{x}}\right) \mathrm{O}_{3-\delta}$ from x-ray absorption spectroscopy, x-ray diffraction, and vibrational spectroscopy," Phys. Rev. B: Condens. Matter, vol. 76, pp. 174107174107, 2007. doi:10.1103/PhysRevB.76.174107

[33]M. Belli and A. Scafati, "X-ray absorption near edge structures (XANES) in simple and complex Mn compounds," Solid State Commun., vol. 35, pp. 355-361, 1980. doi:10.1016/0038-1098(80)905153 ,

[34]F. Bridges, C. H. Booth, M. Anderson, G. H. Kwei, J. J. Neumeier, J. Snyder, J. Mitchell, J.S. Gardner and E. Brosha, "Mn K-edge XANES studies of $\mathrm{La}_{1-x} A_{x} \mathrm{MnO}_{3}$ systems $(A=\mathrm{Ca}, \mathrm{Ba}, \mathrm{Pb})$," Phys. Rev. B, vol. 63, pp. 214405, 2001. doi:10.1103/PhysRevB.63.214405

[35] V. P. Zakaznova-Herzog, H. W. Nesbitt, G. M. Bancroft and J. S. Tse, "High resolution core and valence band XPS spectra of non-conductor pyroxenes," Surf. Sci., vol. 600, pp. 3175-3186, 2006. doi:10.1016/ j.susc.2006.06.012,

[36] N. Batis, P. Delichere and H. Batis, "Physicochemical and catalytic properties in methane combustion of $\mathrm{La}_{1-} x \mathrm{Cax} \mathrm{MnO}_{3 \pm} y(0 \leq x \leq 1$; $-0.04 \leq y \leq 0.24)$ perovskite-type oxide," Appl. Catal. Gen., vol. 282, pp.173-180, 2005. doi:10.1016/j.apcata.2004.12.009

[37]D. Fino, N. Russo, E. Cauda, G. Saracco and V. Specchia, " La-Li-Cr perovskite catalysts for diesel particulate combustion," Catal. Today, vol. 114, pp. 31-39, 2006. doi:10.1016/j.cattod.2006.02.007

[38]S. M. Lima, J. M. Assaf, M. A. Peña and J. L. G. Fierro, "Structural features of $\mathrm{La} 1-x \mathrm{CexNiO}_{3}$ mixed oxides and performance for the dry reforming of methane," Appl. Catal. Gen., vol. 311, pp. 94-104, 2006. doi:10.1016/j.apcata.2006.06.010,

[39] N. Merino, B. Barbero, P. Eloy, L. Cadús, "La1- $x \mathrm{Ca} \mathrm{CoO}_{3}$ perovskitetype oxides: Identification of the surface oxygen species by XPS," 
Appl. Surf. Sci., vol. 253, pp. 1489-1493, 2006 doi:10.1016/ j.apsusc.2006.02.035

[40]S. Petrovic, L. Karanovic, P. Stefanov, M. Zdujic, A. Terlecki-Baricevic, "Catalytic combustion of methane over Pd containing perovskite type oxides," Appl. Catal. B, vol. 58, pp. 133-141, 2005. doi:10.1016/j.apcatb.2004.11.020,

[41]M. Sosulnikov, Y. Teterin, "X-ray photoelectron studies of Ca, Sr and Ba and their oxides and carbonates,"J. Electron Spectrosc. Relat. Phenom., vol. 59, pp. 111-126, 1992. doi:10.1016/0368-2048(92)85002-O 